\title{
Uso do desenho-estória para apreensão de entendimentos e sentimentos de crianças institucionalizadas sobre agressão física
}

Using comic strips to understand perceptions and feelings of children hospitalized due to child physical abuse

Uso de historietas para comprender las percepciones y los sentimientos de los menores hospitalizados por maltrato físico

Como citar este artigo: Lima, Juciara Karla de Souza; Lira, Margaret Olinda de Souza Carvalho e; Oliveira, Jeany Freire de; Campos, Fernando Vitor Alves; Paiva, Levi Olinda Lira de. Uso do desenho-estória para apreensão de entendimentos e sentimentos de crianças institucionalizadas sobre agressão física. Revista Cuidarte. 2021;12(1):e1204.

http://dx.doi.org/10.15649/cuidarte.1204

Revista Cuidarte

Rev Cuid. Ene. - Abril. 2021; 12(1): e1204

doi) http://dx.doi.org/10.15649/cuidarte.1204

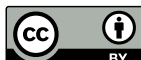

E-ISSN: 2346-3414

(1) Juciara Karla de Souza Lima'

(1) Margaret Olinda de Souza Carvalho e Lira ${ }^{2}$

(1) Jeany Freire de Oliveira ${ }^{3}$

(1) Fernando Vitor Alves Campos

(1) Levi Olinda Lira de Paiva ${ }^{5}$

1 Universidade Federal do Vale do São Franscisco- Petrolina-PE, Brasil. E-mail: jucy_karla@hotmail.com

2 Universidade Federal do Vale do São Franscisco- Petrolina-PE, Brasil. E-mail: margaret.olinda@ univasf.edu.br.

3 Universidade Federal do Vale do São Francisco - Petrolina-PE, Brasil. E-mail: jeanyfroliv@hotmail.com.

4 Universidade Federal do Vale do São Franscisco- Petrolina-PE, Brasil. E-mail:

fnandovitor@hotmail.com.

5 Universidade. Centro Universitário de João Pessoa-Unipê, João PessoaPB, Brasil. E-mail:

leviolinda@gmail.com.

\section{Resumo}

Introdução: A punição corporal de crianças é uma prática recorrente que prejudica o seu desenvolvimento físico e emocional. Objetivo: apreender entendimentos e sentimentos de um grupo de crianças sobre a agressão física praticada por pais ou responsáveis. Materiais e Métodos: estudo descritivo, de abordagem qualitativa e uso do desenho-estória para responder ao estímulo indutor: o que vem à sua cabeça quando você ouve falar: "bater em criança"? Resultados: emergiram sentimentos de amor e ódio, culpa, tristeza, ressentimentos, desejo de vingança, vergonha e o entendimento de agressão física como uma atitude negativa e prejudicial. Conclusão: as crianças demonstraram ansiedade, timidez, agressividade, introspecção e tendência ao isolamento social. Para elas, as punições físicas constituíram episódios negativos que poderiam levá-las à morte, sugerindo que fossem substituídas por diálogo ou castigo.

Palavras chave: Maus-Tratos Infantis; Punição; Criança Abandonada; Criança Acolhida; Defesa da Criança e do Adolescente.
Receibo: 19 de septembro de 2019

Aceito: 22 de maio de 2020

Publicado: 12 de fevereiro de 2021 $\square *$ Correspondência Jeany Freire de Oliveira E-mail: jeanyfroliv@hotmail.com. 


\section{Using comic strips to understand perceptions and feelings of children hospitalized due to child physical abuse}

\section{Abstract}

Introduction: Child physical abuse is a recurrent practice that harms the physical and emotional development of children. Objective: To understand the perceptions and feelings of a group of children who have been physically abused by their parents or caretakers. Materials and Methods: A descriptive qualitative study was conducted using comic strips to respond to the inductive stimulus of what comes to mind when children are mistreated. Results: Feelings of love and hate, guilt, sadness, resentment, desire for vengeance and shame were experienced, as well as the perception of physical abuse as a harmful attitude. Conclusions: Children exhibited anxiety, shyness, aggressiveness, introspection and a tendency to social isolation since child physical abuse represents a tragic episode that would ultimately lead them to death, which is why it is suggested to use dialogue or other methods of punishment instead of physical abuse.

Key words: Child Abuse; Punishment; Child Abandoned; Child Foster; Child Advocacy.

\section{Uso de historietas para comprender las percepciones y los sentimientos de los menores hospitalizados por maltrato físico}

\section{Resumen}

Introducción: El maltrato físico infantil es una práctica recurrente que perjudica el desarrollo físico y emocional de los menores. Objetivo: Entender las percepciones y los sentimientos de un grupo de menores que han sido maltratados físicamente por sus padres o cuidadores. Materiales y métodos: Estudio descriptivo de tipo cualitativo que mediante historietas busca responder al estímulo inductivo de qué se le viene a la mente al escuchar que están maltratando a un niño. Resultados: Se produjeron sentimientos de amor y odio, culpa, tristeza, resentimientos, deseo de venganza y vergüenza, además de percibir el maltrato físico como una actitud negativa y dañina. Conclusiones: Los niños manifestaron ansiedad, timidez, agresividad, introspección y tendencia al aislamiento social, puesto que el maltrato físico se constituye un episodio negativo que los podría llevar a la muerte, por lo que se sugiere que este fuese sustituido por el diálogo u otros castigos.

Palabras clave: Maltrato a los Niños; Castigo; Niño Abandonado; Niño Acogido; Defensa del Niño. 


\section{Introdução}

A violência na infância ao mesmo tempo em que constitui um problema de saúde pública, configura um ato de violação aos direitos humanos. A maioria das situações ocorre no ambiente doméstico, praticada por adultos vinculados às crianças e adolescentes e costuma envolver agressão física e psicológica, negligência, abandono e abuso sexual. Estima-se que sofrem agressão física uma a cada quatro crianças sem diferenciação de gênero, já o abuso sexual é praticado contra uma a cada cinco meninas e um a cada treze meninos ${ }^{1}$.

Nesse contexto de maus-tratos infantis, a agressão física é a mais recorrente, uma vez que é uma conduta adotada por muitas famílias que veem no uso da força física uma forma de educar os filhos. Esse tipo de agressão está entre os motivos para o acolhimento institucional de crianças e adolescentes, documentada como violência doméstica física, comumente associado à negligência na família, dependência química e alcoolismo pelos pais ou outro adulto responsável e abandono pelos pais ou responsáveis².

Dados do relatório mundial sobre violência na infância, constatam que em uma escala global, 67\% das crianças de 1 a 14 anos da América do Sul e Caribe já sofreu punição física disciplinar no ambiente doméstico. No Brasil, $68 \%$ das crianças até 14 anos já sofreu agressão física no ambiente doméstico ${ }^{3}$. Percentuais aproximados são comprovados em $58,9 \%$ das denúncias encaminhadas à Ouvidoria Nacional de Direitos Humanos. Dessas, 57\% são praticadas no ambiente doméstico, 39,4\% por agressão física ${ }^{4}$.

As pesquisas mais recentes mostram que a prática punitiva de crianças e adolescentes no contexto familiar, além de ser uma ameaça à segurança, tem impactos negativos que vão além das lesões físicas, prejudicando o desenvolvimento físico e emocional. Seus efeitos podem se prolongar por toda a vida, predispondo à naturalização e reprodução da violência em suas relações e interações sociais ${ }^{5}$. Os episódios de agressão marcam a memória de pessoas vítimas de agressão na infância, de tal maneira que, independentemente da idade em que se encontram, costumam ter diminuição da capacidade de tomar decisões diante de situações conflituosas ${ }^{6}$.

Também é esperado que em um contexto de punição corporal, ocorra, por parte da criança, a externalização de sentimentos, como baixa autoestima, insegurança, desejos de vinganças, raiva e medo. É neste contexto de violação de direitos, com acolhimento institucional como medida protetiva de crianças e adolescentes, que esta pesquisa objetiva apreender entendimentos e sentimentos de um grupo de crianças sobre a prática de agressão física praticada por pais ou por responsáveis.

\section{Material e métodos}

Este material é um recorte da dissertação de mestrado intitulada: "Representação social de criança sobre agressão física intrafamiliar", uma pesquisa de abordagem qualitativa aprovada pelo Comitê de Ética e Deontologia da Universidade Federal do Vale do São Francisco- CEDEP/ Univasf sob parecer 1.905.865/2017 e desenvolvida em 2017 na cidade de Petrolina-PE. 
Os participantes foram crianças entre seis e dez anos, acolhidas em duas casas de acolhimento institucional que atenderam aos critérios de inclusão de se encontrarem em situação de acolhimento por decisão judiciária e de ter sofrido agressão física no âmbito familiar.

Para preservar o anonimato, elas foram identificadas pelos nomes fictícios: Helicóptero, Huck, Salsicha do Scooby Doo, Sonyc, Camisa 10 do Flamengo, Flash, Super-Homem, Homem-Aranha, Wolverine, Chiken Bell, Princesas Joana, Sofia, Elsa, Barbie e Bela.

Os dados foram obtidos por meio de levantamento em prontuários, observação participante e entrevista individual semiestruturada, facilitada pelo uso do desenho estória, técnica projetiva, por meio da qual a criança se comunica e, entre o real e o imaginário desenvolve a expressão e a representação gráfica de suas vivências ${ }^{7}$. Considerando que a técnica consiste em associar o desenho ao relato da estória, foi disponibilizado papel branco, lápis preto e coloridos, com o seguinte estímulo indutor: o que vem à sua cabeça quando você ouve falar em "bater em criança".

Diante disto, foi solicitado a cada criança que elaborasse um desenho e que, após concluílo, relatasse a estória sobre ele, deixando-a à vontade para falar espontaneamente sobre a produção e os sentimentos despertados ao falar das vivências de agressão física. Deste modo, os resultados, estão, ao mesmo tempo, apresentados e discutidos à luz da literatura vigente sobre punição física na infância e acolhimento institucional como medida protetiva de crianças e adolescentes.

\section{Resultados}

Grupo constituído por 15 crianças, seis meninas e nove meninos com idade prevalente de 10 anos. Quatro pertenciam a famílias, nucleares, constituídas pelos pais e os filhos, quatro a famílias extensas, três a famílias reconstituídas, quatro a famílias monoparentais, sendo duas monoparentais femininas e duas masculinas. Do total de crianças, três eram órfãs: uma de mãe, uma de pai e outra de ambos. Quanto aos autores das agressões físicas, prioritariamente foram mães (9), seguida de pais (6). Contudo, além de pais e mães, três das 15 crianças foram agredidas por outros parentes. Nesse caso, por irmãos e avós.

Ressalte-se que concomitante às agressões físicas, oito crianças sofreram negligência física e abandono, faltando-Ihes suprimento das necessidades básicas, como alimentação, moradia, cuidados de higiene e frequência à escola. Além disto, uma menina foi abusada sexualmente pelo padrasto e um menino foi estimulado pelos pais, a iniciar práticas sexuais com uma menina vizinha.

\section{Relato das produções}

Síntese do primeiro desenho: aproximação e interação

Este primeiro contato individual com as crianças que atenderam aos critérios de inclusão da pesquisa, teve o objetivo de favorecer a aproximação da pesquisadora com cada uma delas e minimizar possíveis desconfortos. Após se apresentar para facilitar a comunicação, iniciou-se cada conversa por meio dos estímulos: "o que você acha de brincar de desenhar? "Então vamos brincar de desenhar", "você pode desenhar sobre o que quiser". Após o término, solicitava-se a cada criança que relatasse a estória sobre o desenho produzido. 
Por meio da observação participante, percebeu-se diferentes reações, graus de motivação e dificuldades para interagir, demonstradas por timidez, ansiedade, vergonha, agressividade e introspecção, marcantes nos participantes Salsicha, Huck, Camisa 10 e Flash, que se limitaram a responder em poucas palavras o que era perguntado. Outras, como o Super-Homem, Homem Aranha, Chiken Bell e as princesas Sofia, Barbie e Elsa, se mostraram comunicativas e interessadas em conversar. A calma, a alegria e o carinho foram mais notados em Helicóptero e nas princesas Joana e Bela.

Síntese do segundo desenho: a estória contada além da agressão física

Favorecida a aproximação e desenvolvida uma relação mais confiável, o segundo encontro teve o intuito de apresentar o objetivo da proposta e convidar cada criança a participar da pesquisa, apresentando-Ihes o Termo de Assentimento Livre e Esclarecido. Pois, apesar da autorização da instituição, por meio do Termo de Consentimento Livre e Esclarecido, a participação das crianças somente ocorreu após a devida concordância delas.

De posse do material, cada criança foi convidada a continuar a brincadeira de desenhar, mediante o estímulo: hoje vamos desenhar o que vem à sua cabeça quando você ouve falar em "bater em criança". Após a conclusão da elaboração, foi solicitado que relatassem a estória sobre o desenho.

Os resultados foram agrupados nas categorias: A culpa despertada na criança que apanha; ambiguidade de sentimentos: amor e ódio; agressividade; ressentimentos e desejo de vingança; danos resultantes da intensidade da força física; ansiedade; resistência passiva e proteção velada dos pais e desejo de retornar ao convívio da família.

\section{A culpa despertada na criança que apanha}

A estória contada nos desenhos produzidos pelas irmãs Barbie e Elsa (Figura 1), traduzem a culpa assumida pela criança punida fisicamente.
A estória contada nos desenhos produzidos pelas irmãs Barbie e Elsa (Figura 1), traduzem a culpa assumida pela criança punida fisicamente

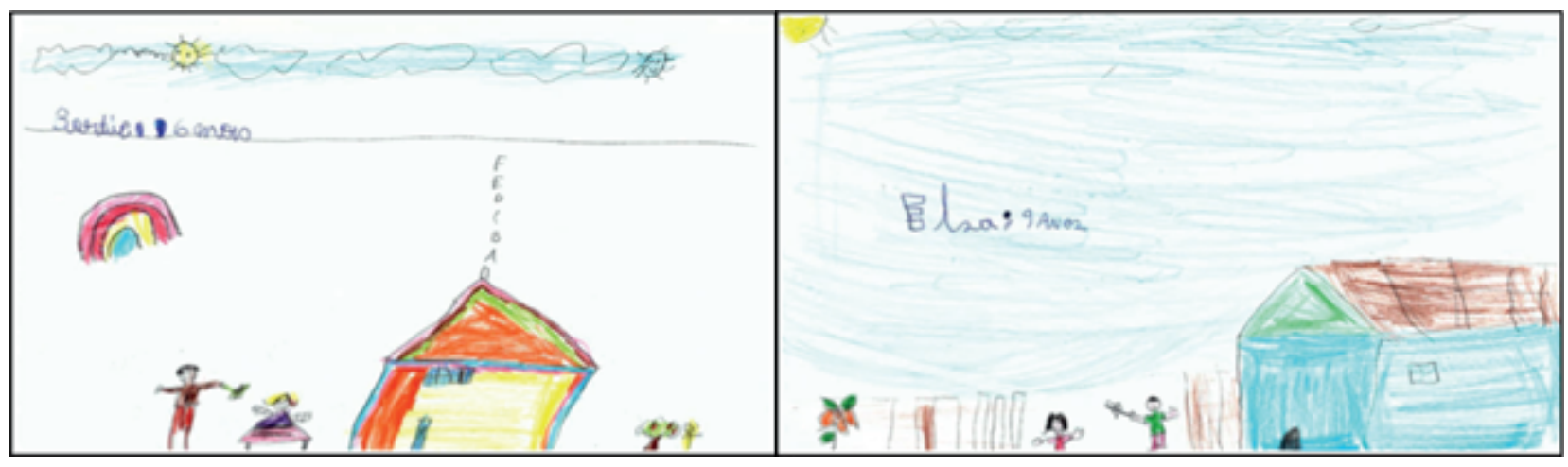

Figura 1. Desenhos das irmãs Barbie e Elsa

Filhas de mãe alcoolista, sofreram negligência e agressão física, além de testemunharem repetitivas cenas de agressão físicas entre os pais. Na narrativa do desenho, Barbie descreve o pai lhe batendo com um cipó. Para ela: 
[...] ele bateu com um cipó, porque eu estava pegando as coisas da minha mãe [...]. (Barbie, 6 anos)

Elsa também se pune e justifica que a agressão física praticada pelo pai, deveu-se à sua desobediência. No desenho, descreve o pai correndo para Ihe bater:

[...] olha, no desenho: ele está correndo com um chicote para me bater, por eu estava brincando com terra...Ele viu e falou: não faça isso, senão eu te dou uma pisa. (Elsa, 10 anos)

Sonyc além de testemunhar repetitivos episódios de agressão física entre os pais, findava sofrendo agressão fisicamente. Informações coletadas em seu prontuário mostram mudanças em seu comportamento: de extrovertido, se tornou triste, agitado e agressivo com colegas e professores. No desenho (Figura 2) ele descreve com tristeza:

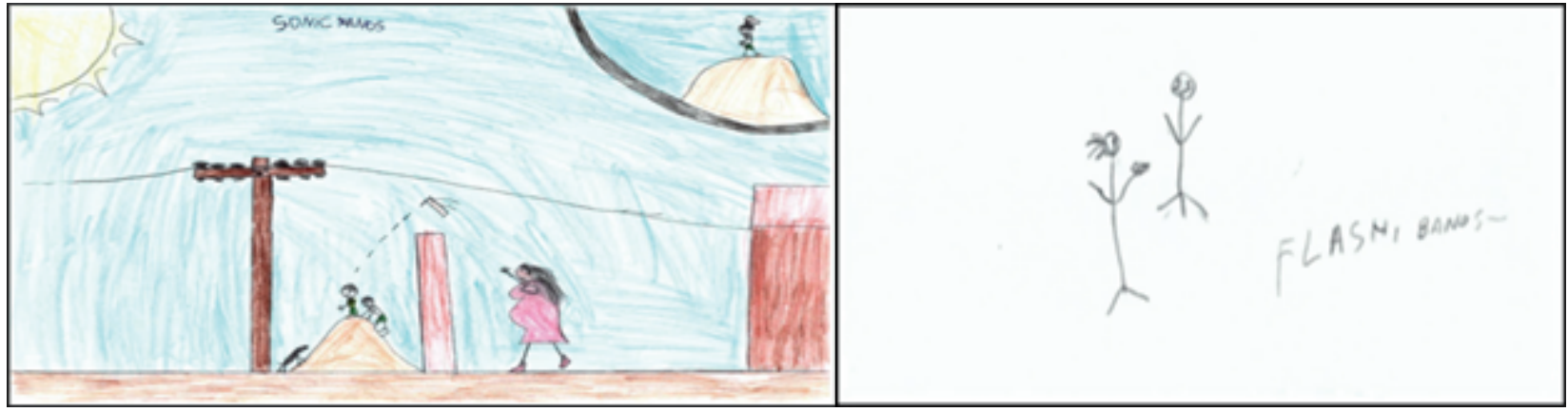

Figura 2. Desenhos de Sonyc e Flash

[...] Quando meus pais bebiam, era briga que acabava em violência, porque eles bebiam tanto que chegavam a mostrar a faca um para o outro! Minha mãe sempre me usou e meu irmão como escudo humano. Aí chamavam palavrões e a gente acabava se envolvendo. Acabava sobrando para a gente... mas neste dia meus pais não beberam (aqui era raiva mesmo). Veja, que minha mãe me arremessou um pedaço de madeira com um prego na ponta [...]. (Sonyc, 10 anos)

Flash mostrou-se envergonhado, calado e pensativo, limitando-se a responder ao solicitado sobre o desenho produzido em preto e branco (Figura 2), em que relata a estória de punição física praticada pela mãe.

[...] Minha mãe me bateu porque eu não a escutei. Como ela não me deixava brincar e ir para quadra, eu desobedecia. Desta vez ela me bateu com uma sandália, mas em outras vezes, apanhei com um chicote [...]. (Flash, 8 anos)

\section{Ressentimentos e desejo de vingança}

As crianças também demostraram ressentimentos e desejo de vingança diante das medidas adotadas por seus responsáveis, chamando a atenção, as reações de Camisa 10 e Wolverine (Figura 3). 


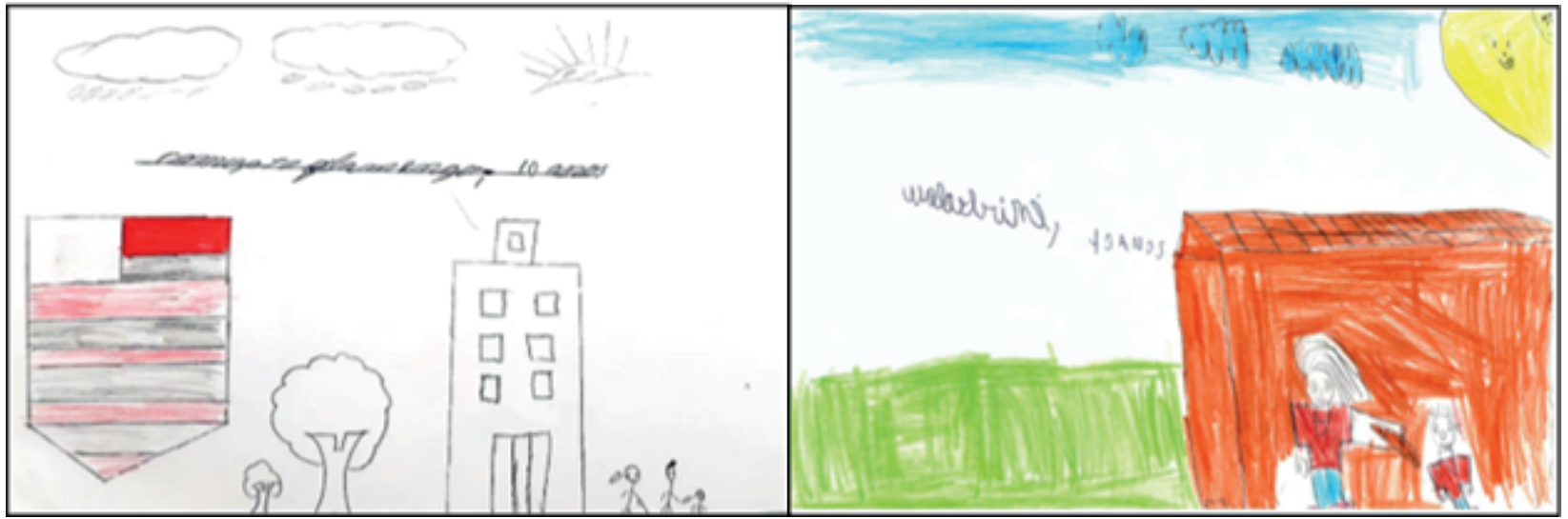

Figura 3. Desenhos de Camisa 10 e Wolverine

Filho de pais separados, Camisa 10 mantém pouco contato com a mãe e é negligenciado pelo pai, que o abandona em casa. Ele não coloriu o desenho (Figura 3) e contou a estória das personagens: ele, seu pai e sua mãe. Relatou que sofria agressão física de ambos:

[...] meu pai já me bateu com corda e minha mãe com um fio de energia [...]. (Camisa 10,8 anos)

Wolverine é órfão de pai e filho de mãe alcoolista, que reconstituiu a família com um homem também alcoolista. De difícil comunicação, ele se mostrou retraído, agressivo e desobediente com a professora. Em sua produção (Figura 3), além de revelar o alcoolismo da mãe, através do copo de bebida que ela porta à mão, chamou a atenção quando ele apontou para cima da casa e descreveu:

[...] Olha o sol brabo, aqui! ... É porque, ele (o sol) está com raiva porque ela (mãe) está me batendo. Aí ficou mais quente e queimou ela quando ela saiu. Olha que ela chega em casa toda fritada... E eu, como ela no jantar... toda queimada...corto os pedaços e como ela [...]. (Wolverine, 7 anos)

\section{Ansiedade}

Menciona-se aqui a Princesa Bela, institucionalizada devido à negligência física e abandono pela mãe, que é usuária de crack.

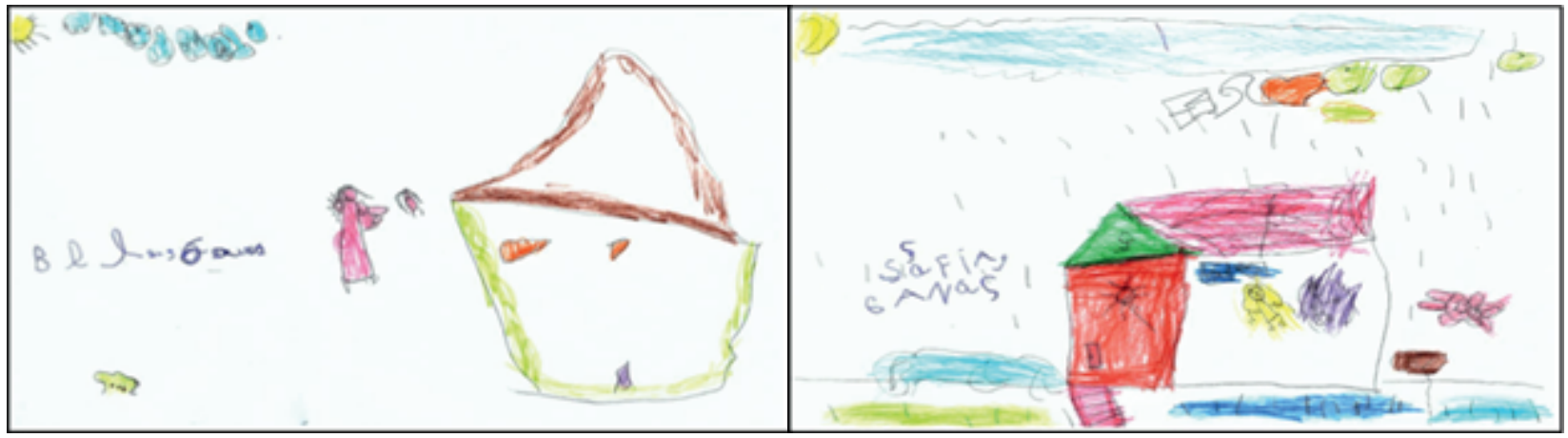

Figura 4. Desenhos de Princesa Bela e Sofia

Na elaboração do desenho (Figura 4), mostrou-se ansiosa ao relatar a agressão física praticada pela mãe: 
Ela me bateu com a mão: primeiro me deu um tapa, depois um murro. (Princesa Bela,6 anos)

Princesa Bela desencadeou um quadro de alotriofagia, síndrome que consiste no consumo de substâncias não comestíveis como lixo, papel, madeira ou terra.

As irmãs, Princesa Joana e Sofia, foram institucionalizadas por negligência física da tia, responsável por elas, já que a mãe se encontrava em situação de reclusão.

Sofia se transporta para a estória do desenho (Figura 4) e relata que:

Ela (mãe) bateu porquê quis. (Sofia,6 anos)

Diz que a mãe lhe deu uma surra porque ela estava teimosa:

Ela bateu no meu braço, mas era para conversar, porque doeu muito. (Sofia,6 anos)

Quanto à Princesa Joana, relata que também foi agredida pela mãe e questiona:

Eu estava brincando e sem querer, joguei a sandália na minha irmã. Então, minha mãe viu e brigou comigo. Eu reclamei, disse: "oxe... nãooo"... Aí, ela bateu na minha mão. Mas ela bateu outras vezes e está errado, porque a violência é uma coisa triste. É errado, não deveria acontecer, deveriam conversar ou colocar de castigo. (Princesa Joana, 9 anos)

\section{Intensidade da força física e danos resultantes}

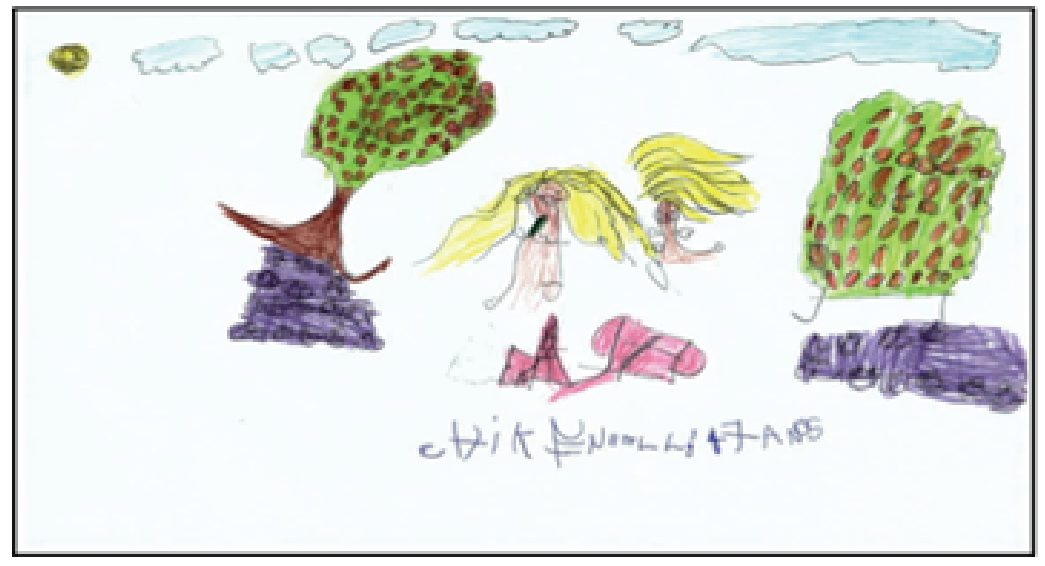

Figura 5. Desenho de Chiken Bell

No desenho (Figura 5), Chiken Bell descreveu:

[...]Minha mãe sempre me batia com chicote, sandália ou cinto. Aqui, é uma árvore bem grandona, com o fruto do bem e do mal. Minha mãe me bateu com um cinto, porque eu não queria ir para cama, queria ficar assistindo TV e ela não deixou e me bateu. Porque violência física é ficar batendo, mordendo, beliscando, fazendo coisas que machucam. (Chiken Bell, 7 anos)

Outra criança que também intensificou este ponto de vista negativo sobre violência física na infância foi Sonyc: 
[...] "Bater na criança é ruim, porquê pode levar à morte; tu já assistiu aquela reportagem na televisão sobre um filho agredindo a própria mãe? Isto aí é totalmente errado para um ser humano. Eu não vou falar nem ser humano, porque quem faz isso com as pessoas que ela mais ama, é... é um monstro, tem que ser um monstro para chegar a quase matar o filho, a mãe, ou o pai [...]. (Sonyc, 10 anos)

\section{Resistência passiva}

As crianças buscam estratégias para sobreviver às agressões físicas praticadas pelos pais ou responsáveis, conforme referido por Homem-Aranha e Elsa.

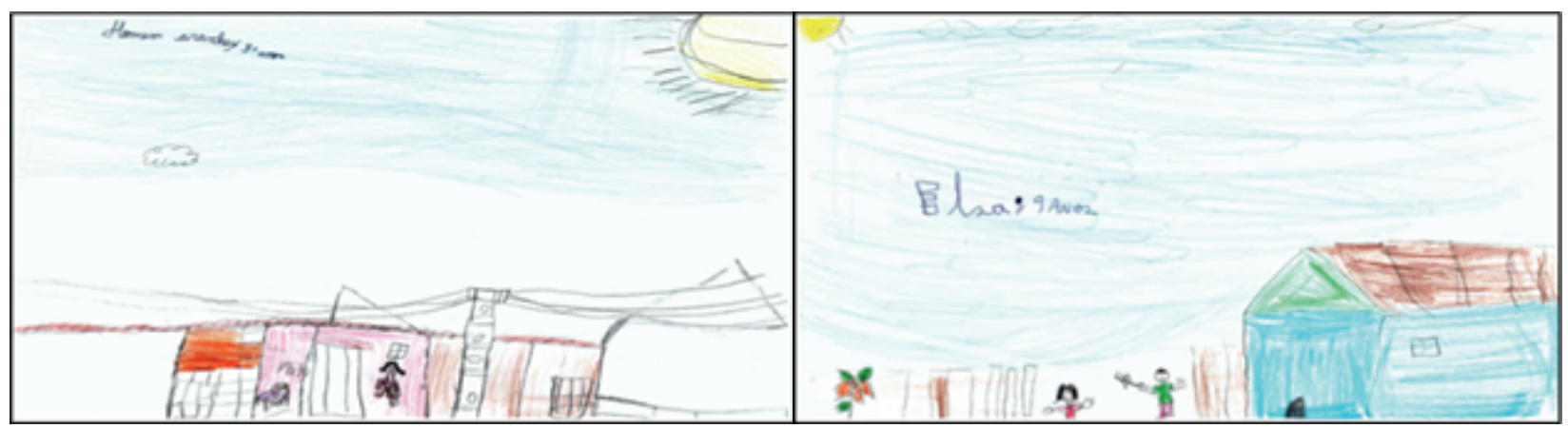

Figura 6. Desenhos de Homem-Aranha e Elsa

Na estória do desenho (Figura 6), o menino relata que está escondido embaixo da cama:

Eu estou lá para dentro do quarto escondido embaixo da cama e ela (avó) está se dirigindo à cama e eu escondidinho, virado para ela não me encontrar, mas ela me viu e jogou a sandália nas minhas costas. (Homem-Aranha, 9 anos)

Já Elsa corre e tranca a porta de casa:

Porque eu estava brincando com terra, aí o meu pai viu e disse: não faça isso de novo, senão eu lhe dou uma pisa! Veja aí: ele está correndo com um chicote para me bater... Aí depois eu corri para dentro, para dentro de casa, fechei a porta e meu pai quebrou a porta. (Elsa, 10 anos)

Além dos depoimentos acima, Wolverine também referiu:

Minha mãe aqui, ela me batia e eu ficava deitado no chão... porquê sim, eu não gostava quando ela batia na minha irmã e eu ficava reclamando... Porque eu não gostava que alguém batesse na minha irmã. Nesse dia ela bateu porque eu estava teimando, subi em cima das telhas, e não quis sair de lá. Doeu muito. (Wolverine, 07 anos)

\section{Proteção velada dos pais e desejo de retornar ao convívio da família}

As crianças demonstram receio de que os desenhos prejudiquem aos pais e conscientemente buscam maneiras de protegê-los:

Não é certo bater, é para colocar de castigo até se comportar, mas ele é meu pai e as meninas que estão aqui vão ficar sabendo, tia... (Elsa, 10 anos) 
Não vou desenhar meu pai batendo em mim, porque eu tenho medo de falar... eu não sei fazer. (Barbie, 6 anos)

\section{Discussão}

Os resultados desta pesquisa mostram a punição corporal como uma estratégia destrutiva para o desenvolvimento da criança, despertando-Ihe sentimento de culpa e prejuízos emocionais ${ }^{6}$. Pois, em seu imaginário infantil, a criança somente apanha porque desagrada aos pais ou responsáveis. Assim, é notório que, embora seja adotada por muitas famílias como prática disciplinar, a exposição a repetidas punições corporais, amplia o risco de a criança apresentar comportamento agressivo ${ }^{8}$.
Os resultados desta pesquisa mostram a punição corporal como uma estratégia destrutiva para o desenvolvimento da criança, despertando-lhe sentimento de culpa e prejuízos emocionais.

Além do sentimento de culpa, percebeu-se outros danos ao desenvolvimento das crianças, associados a esta prática: agressividade, ansiedade, isolamento social e desejos de vingança. Uma metanálise que investigou a associação entre o uso de punição física pelos pais e efeitos negativos na infância, identificou 17 desfechos associados a esta prática, entre eles, alterações emocionais, como agressividade e comportamento antissocial ${ }^{9}$. De maneira que, quanto maior a exposição à agressão física no ambiente doméstico, mais se amplia a possibilidade de os efeitos negativos no desenvolvimento emocional da criança.

Neste sentido, a exposição a repetitivos episódios de punição física, está entre as experiências de nível mais elevado de estresse na infância, denominado estresse tóxico. Esse constitui fator de risco para a saúde e para o desenvolvimento da criança com impactos negativos a curto e a longo prazo ${ }^{10,11}$. De modo que, entre os custos emocionais decorrentes da força física praticada pelos pais ${ }^{12}$ estão os ressentimentos que muitas crianças apresentam.

Outro efeito danoso, a alotriofagia, foi apresentado por uma das crianças. A síndrome que consiste no consumo de substâncias não comestíveis como lixo, papel, madeira ou terra, está classificada como transtorno alimentar, comumente associada a situações estressantes, sobretudo no ambiente familiar, acometendo principalmente adolescentes e jovens, em uma proporção de dez mulheres para cada homem ${ }^{12}$.

Quanto à ansiedade presente nas crianças participantes, é um transtorno emocional frequentemente presente em crianças que sofrem maus-tratos no ambiente doméstico. Pesquisa desenvolvida com 252 crianças e adolescentes, expostas à violência doméstica, 43,7 $\%$ das quais, à agressão física, constatou elevada prevalência $(65,5 \%)$ de alterações na saúde mental, possivelmente associados a esta prática: problemas de conduta, sinais de depressão e ansiedade, dificuldades de relacionamento e de atenção, problemas de concentração e hiperatividade ${ }^{13}$.

Reitera-se que a punição corporal de crianças, seja por meio de palmadas ou pelo uso de objetos, como chinelos, constitui uma estratégia destrutiva utilizada por seus responsáveis para puni-las ou para interrompelas diante de comportamentos que consideram inadequados ${ }^{14}$, que a depender do objeto usado, pode
Além do sentimento de culpa, percebeu-se outros danos ao desenvolvimento das crianças, associados a esta prática: agressividade, ansiedade, isolamento social e desejos de vingança. 
resultar em lesões como cortes, lacerações e até a situações extremas, como a morte. Pesquisa que analisou situações de violência atendidas em serviços de urgência e emergência, identificou o espancamento e a força corporal como as estratégias mais utilizadas na agressão física de crianças, mediante uso de objetos perfurocortantes e contundentes ${ }^{15}$.

É preciso refletir que diante de um adulto, crianças se encontrarão sempre em desvantagem física e emocional, o que já é suficiente para não lhes aplicar punição corporal. Apesar disso, as crianças desta pesquisa se posicionaram, defenderam seus pontos de vista e reprovaram as atitudes punitivas dos pais ou responsáveis. Por não poderem enfrentá-los de modo páreo, utilizaram formas de resistência passiva, como esconder-se embaixo da cama, fingir dormir ou ficar na rua ${ }^{16}$, artimanhas comumente usadas por crianças para despistar o agressor.

As crianças não apenas reprovaram esta estratégia disciplinar, como também deram sugestões de atitudes a ser aplicadas, quando os filhos desobedecem. Alguns estudos trazem que apesar de ainda frequente, esta estratégia educativa tradicional vem sendo substituída por alternativas pautadas no diálogo para orientar os filhos ${ }^{17}$, iniciativas que buscam trabalhar práticas parentais positivas, substitutivas de práticas disciplinares disfuncionais com a punição física da criança ${ }^{18}$.

No Brasil, uma iniciativa positiva foi a promulgação da Lei $n^{\circ} 13.010^{19}$ que altera o Estatuto da Criança e do Adolescente ${ }^{20}$ no que se refere ao direito de crianças e adolescentes serem orientadas e cuidadas, isentas da utilização de castigos físicos ou tratamentos degradantes. Conhecida como "Lei menino Bernardo" ou "Lei da Palmada", sua finalidade é coibir essa estratégia destrutiva e abolir a cultura da punição física de crianças ${ }^{21}$.

Percebe-se que, apesar das agressões sofridas e de presenciarem constantes agressões entre os pais, existiu uma proteção velada dos pais pelas crianças, além de ser nítido o desejo delas de reintegração familiar. Contudo, constatou-se que não houve êxito nas tentativas de reintegração familiar, cujos vínculos foram enfraquecidos devidos ao alcoolismo, uso de crack e constantes agressões físicas entre os pais. Pesquisa que avaliou a qualidade de vínculo familiar de 63 crianças, identificou presença de violência física, emocional ou sexual em 17 famílias, quatro delas com comprometimento do vínculo parental associado ao alcoolismo e a agressões físicas e verbais entre os pais e maus-tratos infantis ${ }^{22}$.

\section{Considerações finais}

O Desenho Estória foi o gatilho para que crianças que sofreram agressão física no ambiente familiar expressassem pontos de vista e sentimentos sobre a adoção dessa prática punitiva. Seu uso facilitou a aproximação, reflexões e expressão de sentimentos de crianças sobre punição corporal como medida educativa.

Por meio dos desenhos elaborados elas externaram sentimentos e demonstraram reprovação a essa atitude. Diante da desvantagem física e emocional em relação ao adulto agressor, buscaram estratégias de sobrevivência e de adaptação à situação se reintegrarem às suas famílias. No entanto, as tentativas não tiveram êxito, o que prolongou a permanência das crianças na instituição de acolhimento.

A limitação do estudo se deve ao fato de não poder generalizar os resultados, considerando que tratam-se de dados obtidos em apenas um cenário. No entanto, as informações são relevantes para o esclarecimento e sensibilização da sociedade sobre os efeitos danosos da prática de punição física na saúde e desenvolvimento da criança. 
Conclui-se que o itinerário para combater a agressão física de crianças no ambiente familiar, passa por mudanças culturais sobre o papel da família e pelo reconhecimento da criança como sujeito de direitos.

Conflito de interesses: Os autores declaram que não houve conflito de interesses.

Fonte de financiamento: Coordenação de Aperfeiçoamento de Pessoal de Nível Superior (CAPES).

\section{Referências}

1. OPAS. INSPIRE. Sete estratégias para pôr fim à violência contra crianças. Washington, D.C.: OPAS, 2017.

2. Constantino P, Assis SG, Mesquita VSF. Crianças, Adolescentes e famílias em SAl. In: Assis SG, Farias LOP, editors. Levantamento Nacional das Crianças e Adolescentes em Serviço de Acolhimento. São Paulo: Hucitec; 2013. p. 160-220.

3. Unicef. Know Violence in Childhood. Ending Violence in Childhood. Global Report, 2017.

4. Brasil. Ministério dos Direitos Humanos. Ouvidoria Nacional dos Direitos Humanos. Balanço Ouvidoria. Brasil, 2018.

5. Moura JP, Almeira JLS, Araújo JP, Menezes RMP, Chaves AEP. Implicações da violência na infância e adolescência. Ver. Univ. Vale Rio Verde. 2014;12(1):513-524. http://dx.doi.org/10.5892/ruvrd.v12i1.1415

6. Nunes AJ, Sales MCV. Violência contra crianças no cenário brasileiro. Ciênc. Saúde Colet. 2016; 21(3):871-880. http://dx.doi.org/10.1590/1413-81232015213.08182014

7. Correia CC. O desenho na avaliação pedagógica e psicopedagógica. Ciência Atual. 2016;8(2):05-17.

8. Santini PM, Williams LCA. Parenting Programs to Prevent Corporal Punishment: A Systematic Review. Paidéia (Ribeirão Preto). 2016;26(63):121-129.

http://dx.doi.org/10.1590/1982-43272663201614

9. Gershoff ET, Grogan-Kaylor A. Spanking and child outcomes: Old controversies and new meta-analyses. J. Fam. Psychol. 2016;30(4):453-469. https://doi.org/10.1037/fam0000191

10.Linhares ABM. Estresse precoce no desenvolvimento: impactos na saúde e mecanismos de proteção. Estud psicol (Campinas) [online]. 2016;33(4):587-599.

http://dx.doi.org/10.1590/1982-02752016000400003.

11.Gershoff ET. Should Parents' Physical Punishment of Children Be Considered a Source of Toxic Stress That Affects Brain Development? Fam. Relat. 2016;65:151-62.

https://doi.org/10.1111/fare.12177

12.Bandeira AG, Gabriel JE. Impactos dos transtornos alimentares maternos sobre o desenvolvimento físico e psicossocial dos filhos: uma revisão sistemática. Rev. Ciênc. Méd. Biol. 2016;15(1):88-94. http://dx.doi.org/10.9771/cmbio.v15i1.14461

13.Hildebrand NA, Celeri EHRV, Morcillo AM, Zanolli ML. Violência doméstica e risco para problemas de saúde mental em crianças e adolescentes. Psicol. Reflex. Crit. 2015;28(2):213221. http://dx.doi.org/10.1590/1678-7153.201528201

14.Bolze SDA, Schmidt B, Böing E, Crepaldi MA. Conflitos Conjugais e Parentais em Famílias com Crianças: Características e Estratégias de Resolução. Paidéia (Ribeirão Preto). 2017;27(supl.1):457-465. http://dx.doi.org/10.1590/1982-432727s1201711

15.Avanci JQ, Pinto LW, Assis SG. Atendimento dos casos de violência em serviços de urgência e emergência brasileiros com foco nas relações intrafamiliares e nos ciclos de vida. Ciênc. Saúde Colet. 2017;22(9):2825-2840. http://dx.doi.org/10.1590/1413-81232017229.13352017 
16.Lira MOSC, Nitschke RG, Rodrigues AD, Rodrigues VP, Couto TM, Diniz NMF. Sobrevivendo ao abuso sexual no cotidiano familiar: formas de resistência utilizadas por crianças e adolescentes. Texto Contexto Enferm. 2017;26(2):01-09.

http://dx.doi.org/10.1590/0104-07072017000050016

17.Carrillo-Urrego A. Castigos en la crianza de los hijos e hijas: un estado de la cuestión. Rev. Latinoam.Cienc.Soc.NiñezJuv.2018;16(2):719-740.https://doi.org/10.11600/1692715x.16206

18.Guisso L, Bolze SDA, Viera ML. Práticas parentais positivas e programas de treinamento parental: uma revisão sistemática da literatura. Contextos Clínicos. 2019;12(1):226-55. https://doi.org/10.4013/ctc.2019.121.10

19.Brasil. Casa civil. Lei n.13.010, de 26 de junho de 2014. Altera a Lei no 8.069, de 13 de julho de 1990 (Estatuto da Criança e do Adolescente), para estabelecer o direito da criança e do adolescente de serem educados e cuidados sem o uso de castigos físicos ou de tratamento cruel ou degradante, e altera a Lei no 9.394, de 20 de dezembro de 1996. Brasília, DF, 2014.

20.Brasil. Lei Federal N. 8069, de 13 de julho de 1990. Estatuto da Criança e do Adolescente. Brasília, DF, 1990.

21.Souto DF, Zanin L, Ambrosano GMB, Flório FM. Violência contra crianças e adolescentes: perfil e tendências decorrentes da Lei n 13.010. Rev. Bras. Enferm. 2018;71(supl.3):1237-1246. http://dx.doi.org/10.1590/0034-7167-2017-0048

22.Leoncio ET, Souza SRP, Machado JLM. Degradação do vínculo parental e violência contra a criança: o uso do genograma familiar na prática clínica pediátrica. Rev. Paul. Pediatr. 2017;35(2):185-190. http://dx.doi.org/10.1590/1984-0462/;2017;35;2;00009 